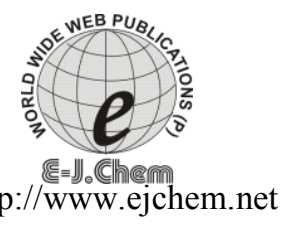

ISSN: 0973-4945; CODEN ECJHAO

E-Journal of Chemistry

2012, 9(4), 1885-1896

\title{
Bismuth Basic Nitrate as a Novel Adsorbent for Azo Dye Removal
}

\author{
E. A. ABDULLAH ${ }^{a^{*}}$, A. H. ABDULLAH ${ }^{\mathrm{a}, \mathrm{b}}, \mathrm{Z}$ ZAINAL $^{\mathrm{a}, \mathrm{b}}$, \\ M. Z.HUSSEIN ${ }^{\mathrm{a}, \mathrm{b}}$, AND T. K. BAN ${ }^{\mathrm{a}}$ \\ ${ }^{a}$ Department of Chemistry, Faculty of Science \\ Universiti Putra Malaysia, 43400, UPM Serdang, Selangor, Malaysia \\ ${ }^{\mathrm{b}}$ Advanced Material and Nanotechnology Laboratory \\ Institute of Advanced Technology, Universiti Putra Malaysia, 43400 \\ UPM Serdang, Selangor, Malaysia \\ yemenahmed2009@gmail.com
}

Received 20 October 2011; Accepted 30 December 2011

\begin{abstract}
Bismuth basic nitrate $(\mathrm{BBN})$ and its $\mathrm{TiO}_{2}-\mathrm{Ag}$ modified sorbent, PTBA were successfully synthesized via a precipitation method. The structural characteristics of prepared sorbents were determined through different analytical techniques. The potential use of prepared sorbents for organic compounds' removal was evaluated using Methyl Orange and Sunset Yellow dyes as model pollutants in aqueous solutions. The experimental results showed that the presence of $\mathrm{TiO}_{2}$ and $\mathrm{Ag}$ particles during the crystal growth of bismuth basic nitrate has an effect on the crystal structure, point of zero charge $\left(\mathrm{pH}_{\mathrm{pzc}}\right)$, pore volume and diameter. The lower binding energy of Ti $2 p$ core level peak indicates the octahedral coordination of $\mathrm{TiO}_{2}$ particles on the PTBA surface. The alteration of hydrophilic-hydrophobic characteristics of sorbent's surface improves the adsorptive performance of the modified sorbent and provides an efficient route for organic contaminants' removal from aqueous solutions.
\end{abstract}

Keywords: Hydrophilic character, Organic contaminants, Point of zero charge $\left(\mathrm{pH}_{\mathrm{pzc}}\right), \mathrm{X}-\mathrm{ray}$ photoelectron spectroscopy.

\section{Introduction}

Bismuth basic nitrate $(\mathrm{BBN})$ is a bismuth oxide based nitrate compound that belongs to the $\mathrm{Bi}_{2} \mathrm{O}_{3}-\mathrm{N}_{2} \mathrm{O}_{5}-\mathrm{H}_{2} \mathrm{O}$ group and consists of nitrate anions, water molecules and cage-like $\left[\mathrm{Bi}_{6} \mathrm{O}_{4+\mathrm{x}}(\mathrm{OH})_{4-\mathrm{x}}\right]^{6-\mathrm{x}}$ polycations, where $\mathrm{x}=0$ and $1^{1,2}$. Due to the weak of hydrogen bonds, water molecules can be easily lost in the structures making some confusion about water content of these compounds ${ }^{3}$. Although about 15 compounds of bismuth basic nitrates have already been reported in the literature since the $17^{\text {th }}$ century, only a few have been confirmed by investigators. This is due to the difficulties in their chemical analysis and the problems associated with the isolation of a pure phase ${ }^{4}$. A further difficulty associated with structural 
prediction is that surface chemistry. The relative uncertainty in this area does not solely preclude an exact description of these materials, but might also limit their critical applications.

The medical applications of BBN have been reported ${ }^{5}$. They are also used as a precursor for bismuth oxide in soft chemistry ${ }^{6}$. In addition, due to its low solubility, it is also used in anion-exchange reactions for the removal of halides and several Oxoanions ${ }^{7,8}$. To our knowledge, the application of BBN as an adsorbent in environmental protection has not been reported.

Recently, various modification techniques in environmental protection such as; mild oxidation $^{9}$, incorporation of magnetic nanoparticles ${ }^{10}$, use of organic cationic surfactant ${ }^{11}$, etc, have been applied to develop the surface chemistry and adsorbability of sorbent materials. The ability of $\mathrm{TiO}_{2}$ to produce positively charged surfaces of silica has also led to enhanced adsorption capacity ${ }^{12}$. The addition of silver on $\mathrm{TiO}_{2}$ surface was reported as an efficient tool for the selective removal of polycyclic aromatic sulphur ${ }^{13}$.

The aim of our research is to gain new insights to help describe the surface chemistry of the BBN sorbent through the use of different analytical techniques. The effect of $\mathrm{TiO}_{2}$ and $\mathrm{Ag}$ additions on the surface chemistry of BBN was also investigated. Methyl Orange (MO) and Sunset Yellow (SY) dyes were used as model pollutants to evaluate the adsorption behaviour.

\section{Experimental}

Bismuth nitrate penta-hydrate, $\mathrm{Bi}\left(\mathrm{NO}_{3}\right)_{3} \cdot 5 \mathrm{H}_{2} \mathrm{O}$ (98\%), nitric acid, $\mathrm{HNO}_{3}(65 \%)$ and ammonium hydroxide, $\mathrm{NH}_{3} \cdot \mathrm{H}_{2} \mathrm{O}(25 \%)$, were purchased from ACROS organic USA, Fisher Scientific, MERCK Germany, respectively. These chemicals were used as starting materials for the synthesis of BBN. Titanium dioxide, P25 $\left(\mathrm{TiO}_{2}\right)$ and silver nitrate, $\mathrm{AgNO}_{3}$, obtained from EVONIK Degussa, GERCHEM Germany, respectively, were used for the surface modification of BBN. Methyl Orange dye, MO, and Sunset Yellow, SY dyes were obtained from Sigma-Aldrich and Aldrich, USA, respectively and used as model pollutants. Ammonium hydroxide was diluted to $50 \% \mathrm{v} / \mathrm{v}$ prior to use while all reagents were used without further purification or modification.

\section{Synthesis of BBN}

BBN was synthesized by adding ammonium hydroxide to a $20 \mathrm{~mL}$ concentrated $\mathrm{HNO}_{3}$ solution containing $10 \mathrm{~g}$ of $\mathrm{Bi}\left(\mathrm{NO}_{3}\right)_{3} \cdot 5 \mathrm{H}_{2} \mathrm{O}$ with continuous stirring until the solution's $\mathrm{pH}$ reached 9. The suspension was then aged with vigorous stirring for $1 \mathrm{~h}$. The precipitate obtained was filtrated, washed with distilled water and oven-dried overnight at $383 \mathrm{~K}$.

\section{Synthesis of $\mathrm{TiO}_{2}-\mathrm{Ag}$ modified bismuth basic nitrate, PTBA}

$\mathrm{TiO}_{2}$-Ag-modified bismuth basic nitrate (PTBA) was synthesized via precipitation method by applying some modifications in the previously described method. Titanium dioxide, $\mathrm{TiO}_{2}$ $(0.5 \mathrm{~g})$ and $\mathrm{AgNO}_{3}(0.175 \mathrm{~g})$, were added to a $20 \mathrm{~mL}$ concentrated $\mathrm{HNO}_{3}$ solution containing $10 \mathrm{~g}$ of $\mathrm{Bi}\left(\mathrm{NO}_{3}\right)_{3} \cdot 5 \mathrm{H}_{2} \mathrm{O}$. The suspension was aged with vigorous stirring for $30 \mathrm{~min}$. Ammonium hydroxide was added to adjust the $\mathrm{pH}$ of the suspension to 9 with continuous stirring. The mixture was further aged with vigorous stirring for $1 \mathrm{~h}$. The precipitate obtained was filtered, washed with distilled water and oven-dried overnight at $383 \mathrm{~K}$.

\section{Characterization}

The structure and phase composition of the adsorbents were identified by X-ray powder diffraction (XRD) patterns in the $2 \theta$ range of $10-70^{\circ}$ with a scan speed of $0.05^{\circ} / \mathrm{sec}$ on a 
X'PERT-PRO diffractometer using $\mathrm{CuK}_{\infty}$ radiation. The nature of the surface groups appeared on prepared sorbents was explored by Fourier transformed infrared. The spectra was recorded on a Perkin-Elmer spectrum 100 series in the range of $4000-280 \mathrm{~cm}^{-1}$ under the attenuated total reflection (ATR) mode using a diamond module. The thermal stability and decomposition products were investigated by Thermogravimetric analysis. The thermogram was recorded using a TGA/SDTA 851 Perkin Elmer thermal analyzer. The sample was heated in nitrogen gas flowing at $50 \mathrm{ml} \mathrm{min}^{-1}$ with a heating rate of $2 \mathrm{~K} \mathrm{~min}{ }^{-1}$ from room temperature up to $1073 \mathrm{~K}$. $\mathrm{N}_{2}$ adsorption-desorption isotherm of synthesized sorbent was measured at $77 \mathrm{~K}$ on a Quantachrome AS1WinTM version 2.0 sorptometer. The surface area and pore size distribution were determined using Brunauer-Emmett-Teller (BET) and Barrett-Joyner-Halenda (BJH) methods. The $\mathrm{pH}$ of the point of zero charge $\left(\mathrm{pH}_{\mathrm{pzc}}\right)$ was determined by the batch equilibrium method. Microstructure characterization was performed using a LEO 912AB Energy filter transmission electron microscope (TEM), operated at $80 \mathrm{kV}$ and a JEOL JSM 6400 scanning electron microscope (SEM). The chemical environment of the sorbent surface was determined by X-ray photoelectron spectroscopy (XPS). The spectra were acquired at room temperature with an XPS AXIS ULTRA spectrometer using an Al-K $\alpha(1486.6 \mathrm{eV})$ monochromatic radiation source. The concentration of Ag was determined by a Thermo Scientific S series atomic absorption spectrometer (AAS) using an air-acetylene flame at a wavelength of $328.1 \mathrm{~nm}$.

\section{Batch adsorption studies}

One gram of prepared sorbents was suspended in $1.0 \mathrm{~L}$ of dye solution $\left(40 \mathrm{mg} \mathrm{L}^{-1}\right)$. The suspension was magnetically stirred for $2 \mathrm{~h}$ at $298 \mathrm{~K}$. At pre-determined time intervals, the solution was separated by a syringe filter of $0.45 \mu \mathrm{m}$, and the dye concentration was analyzed through a UV-1650 PC Shimadzu spectrophotometer at the maximum wavelength after appropriate dilution. The sorption capacities of the adsorbent were reported as a function of the remaining dye concentration using the mass balance equation:

$$
Q=\left(C_{0}-C_{e}\right) \frac{V}{m_{s}}
$$

where $Q$ is the amount of dye adsorbed onto a unit amount of the adsorbent $\left(\mathrm{mg} \mathrm{g}^{-1}\right), C_{0}$ is the initial concentration of dye in solution, $C_{e}$ is the equilibrium total concentration of dye in solution $\left(\mathrm{mg} \mathrm{L}^{-1}\right), V$ is the volume of the solution (L) and $m_{s}$ is the dry weight of the adsorbent used (g). The experiments were performed in triplicate.

\section{Results and Discussion}

\section{$X$-ray powder diffraction (XRD)}

A Phase structure of prepared sorbents was obtained from the XRD results. The XRD patterns of BBN and PTBA are shown in Figure 1. Since the XRD patterns and the crystal structure of synthesized BBN and PTBA compounds are not available in the ICDD database, the synthesized sorbents were indexed and compared to those reported by Henry et al. ${ }^{4}$. The refined cell constants are $\mathrm{a}=15.8694$ (67) $\AA, \mathrm{b}=14.9961$ (104) $\AA, \mathrm{c}=18.2046$ (57) $\AA$ and $\beta$ $=107.11(0.02)^{\circ}$. These results imply that $\mathrm{TiO}_{2}$ cannot substitute the $\mathrm{Bi}^{3+}$ in the crystal lattice which is may be attributed to low temperature, but is instead deposited on BBN's surface. However, the growth directions or crystallographic orientations $<\mathrm{hkl}>$ are different, which indicate a change in the crystal structure. In accordance with TGA results, $\mathrm{TiO}_{2}$ and Ag particles influenced the precipitation process, which lead to a change in the chemical 
composition of PTBA. $\mathrm{TiO}_{2}$ peaks are not clearly seen in the XRD patterns. However, through careful observation, the overlapping behaviour can be detected. An anatase peak was observed at $2 \theta=25.36^{\circ}$ while the rutile peak was overlapped with the main peak of PTBA. Similar overlapping behaviour was observed in Yamashita and Choi's results with $\mathrm{ZrTiO}_{4} / \mathrm{Bi}_{2} \mathrm{O}_{3}{ }^{14}$. An XRD pattern for silver is not observed due to its low concentration $(5 \% \mathrm{~mol})$. The crystallite sizes of the samples estimated by using the Debye-Scherrer equation for the most intense diffraction peaks [(105) and (025)] are $62.3 \mathrm{~nm}$ and $35.6 \mathrm{~nm}$ for BBN and PTBA, respectively.

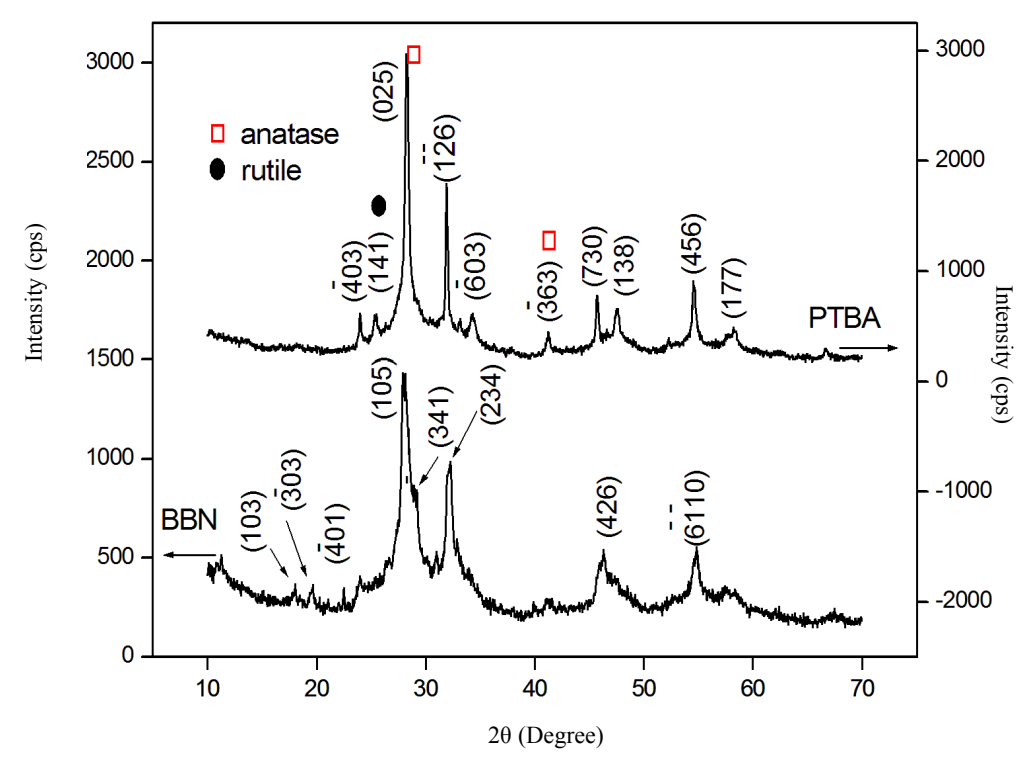

Figure 1. XRD patterns for bismuth basic nitrate, $\mathrm{BBN}$ and $\mathrm{TiO}_{2}-\mathrm{Ag}$ modified sorbents.

\section{Fourier transformed infrared spectroscopy (FTIR)}

The type of functional groups on the surface of prepared sorbents was detected using FT-IR spectroscopy. The corresponding FTIR spectra of BBN and PTBA (Figure 2) show broad absorption bands at $3450 \mathrm{~cm}^{-1}$ and $3220 \mathrm{~cm}^{-1}$ that can be attributed to the stretching modes of lattice water and hydroxyl groups, respectively ${ }^{15,16}$. Broad absorption bands around 1274 and $1310 \mathrm{~cm}^{-1}$ can be assigned to $\mathrm{NO}_{3}^{-}$groups on BBN and PTBA, respectively. These results indicate the ionic nature of nitrate groups. However, the absorption bands at $1031 \mathrm{~cm}^{-1}$ and $1025 \mathrm{~cm}^{-1}$ show the presence of mono-dentate nitrate group ${ }^{17}$. The absorption bands appearing in the range of $800-300 \mathrm{~cm}^{-1}$ can be attributed to the stretching modes of Bi-O bonds. The locations of metal-oxide stretching modes are in agreement with those reported by other investigators for bismuth oxide systems ${ }^{18,19}$.

\section{Thermogravimetric analysis (TGA)}

The thermal stability of BBN and PTBA sorbents was evaluated by thermogravimetric analysis (TGA) (Figure 3). It was clear that the dehydration starts at a relatively low temperature, which indicates the weakness of the hydrogen bonds in the crystal structure. The total weight loss of $25.54 \%$ and $15.97 \%$ for BBN and PTBA, respectively, which are very close to the calculated values of $25.79 \%$ and $15.76 \%$ suggests that the prepared 
sorbents are of compositions $\mathrm{Bi}_{6} \mathrm{O}_{4}(\mathrm{OH})_{4}\left(\mathrm{NO}_{3}\right)_{6} .7 \mathrm{H}_{2} \mathrm{O}$ and $\mathrm{Bi}_{6} \mathrm{O}_{6}(\mathrm{OH})_{2}\left(\mathrm{NO}_{3}\right)_{4} \cdot 1.5 \mathrm{H}_{2} \mathrm{O}$, respectively. Therefore, one can conclude that the addition of $\mathrm{TiO}_{2}$ and $\mathrm{Ag}$ particles have influenced the chemical composition of PTBA sample. The decomposition stages, experimental and calculated weight loss values are summarized in Table 1.

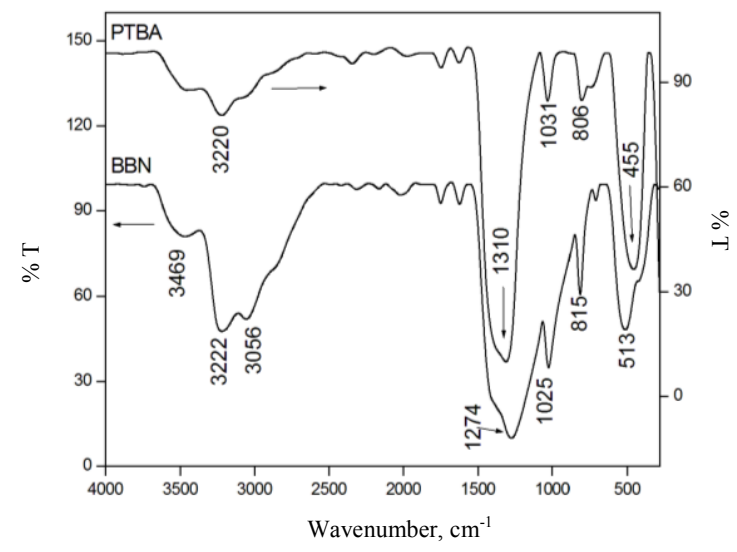

Figure 2. FTIR spectra of synthesized and modified BBN sorbents.
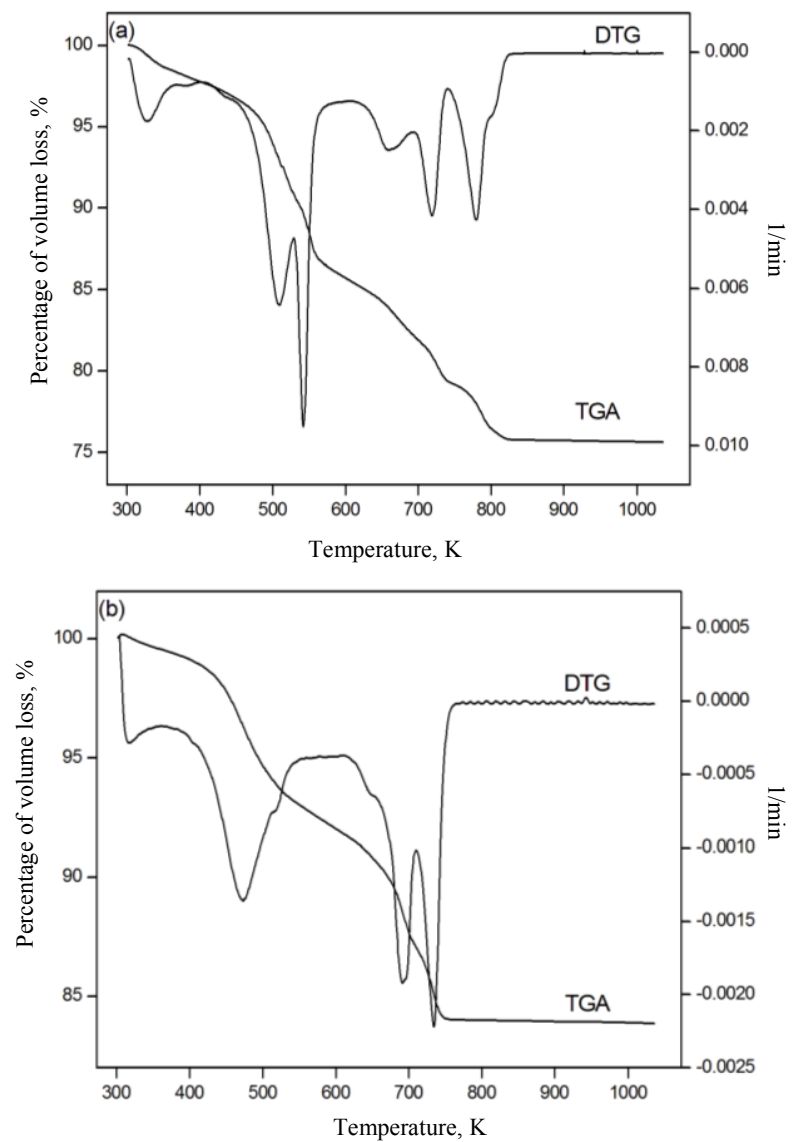

Figure 3. Thermogravimetric analysis (a) BBN and (b) PTBA. 
Table 1. Thermal decomposition stages of suggested formula of BBN and PTBA sorbents.

\begin{tabular}{|c|c|c|c|c|}
\hline \multirow{2}{*}{$\begin{array}{l}\text { Decomp. Temp }{ }^{\mathrm{a}}, \\
(\mathrm{K})\end{array}$} & \multicolumn{2}{|c|}{ Weight lost, \% } & \multirow{2}{*}{ Inference } & \multirow{2}{*}{ Formula } \\
\hline & Obsd. value $^{b}$ & Calc. value ${ }^{\text {c }}$ & & \\
\hline \multicolumn{5}{|c|}{$\mathrm{Bi}_{6} \mathrm{O}_{4}(\mathrm{OH})_{4}\left(\mathrm{NO}_{3}\right)_{6} \cdot 7 \mathrm{H}_{2} \mathrm{O}(\mathrm{BBN})$} \\
\hline $301-345$ & 2.744 & 2.866 & $3 \mathrm{H}_{2} \mathrm{O}$ & $\begin{array}{c}\mathrm{Bi}_{6} \mathrm{O}_{4}(\mathrm{OH})_{4}\left(\mathrm{NO}_{3}\right)_{6} \cdot 4 \mathrm{H}_{2} \\
\mathrm{O}\end{array}$ \\
\hline $432-511$ & 7.317 & 7.113 & $4 \mathrm{H}_{2} \mathrm{O}+\mathrm{NO}_{3}$ & $\mathrm{Bi}_{6} \mathrm{O}_{4}(\mathrm{OH})_{4}\left(\mathrm{NO}_{3}\right)_{5}$ \\
\hline $511-544$ & 4.119 & 4.034 & $\mathrm{~N}_{2} \mathrm{O}_{3}$ & $\mathrm{Bi}_{6} \mathrm{O}_{7}(\mathrm{OH})_{4}\left(\mathrm{NO}_{3}\right)_{3}$ \\
\hline $544-616$ & 2.926 & 3.291 & $\mathrm{NO}_{3}$ & $\mathrm{Bi}_{6} \mathrm{O}_{7}(\mathrm{OH})_{4}\left(\mathrm{NO}_{3}\right)_{2}$ \\
\hline $616-672$ & 2.687 & 2.760 & $\mathrm{H}_{2} \mathrm{O}+2 \mathrm{OH}$ & $\mathrm{Bi}_{6} \mathrm{O}_{8}\left(\mathrm{NO}_{3}\right)_{2}$ \\
\hline $673-715$ & 2.419 & 2.442 & $\mathrm{NO}_{2}$ & $\mathrm{Bi}_{6} \mathrm{O}_{9} \mathrm{NO}_{3}$ \\
\hline $719-816$ & 3.329 & 3.290 & $\mathrm{NO}_{3}$ & $3 \mathrm{Bi}_{2} \mathrm{O}_{3}$ \\
\hline Total weight loss & 25.54 & 25.79 & & \\
\hline \multicolumn{5}{|c|}{$\mathrm{Bi}_{6} \mathrm{O}_{6}(\mathrm{OH})_{2}\left(\mathrm{NO}_{3}\right)_{4} \cdot 1.5 \mathrm{H}_{2} \mathrm{O}(\mathrm{PTBA})$} \\
\hline $304-380$ & 0.755 & 0.814 & $0.75 \mathrm{H}_{2} \mathrm{O}$ & $\begin{array}{c}\mathrm{Bi}_{6} \mathrm{O}_{6}(\mathrm{OH})_{2}\left(\mathrm{NO}_{3}\right)_{4} . \\
0.75 \mathrm{H}_{2} \mathrm{O}\end{array}$ \\
\hline $381-558$ & 6.493 & 6.359 & $\begin{array}{c}0.75 \mathrm{H}_{2} \mathrm{O}+ \\
\mathrm{N}_{2} \mathrm{O}_{4}\end{array}$ & $\mathrm{Bi}_{6} \mathrm{O}_{8}(\mathrm{OH})_{2}\left(\mathrm{NO}_{3}\right)_{2}$ \\
\hline $558-630$ & 1.443 & 1.537 & $1.5 \mathrm{OH}$ & $\mathrm{Bi}_{6} \mathrm{O}_{8}(\mathrm{OH})_{0.5}\left(\mathrm{NO}_{3}\right)_{2}$ \\
\hline $629-710$ & 4.369 & 4.279 & $0.5 \mathrm{OH}+\mathrm{NO}_{3}$ & $\mathrm{Bi}_{6} \mathrm{O}_{8} \mathrm{NO}_{3}$ \\
\hline $710-757$ & 3.045 & 2.773 & $\mathrm{NO}_{2}$ & $3 \mathrm{Bi}_{2} \mathrm{O}_{3}$ \\
\hline Total weight loss & 15.97 & 15.76 & & \\
\hline
\end{tabular}

${ }^{a}$ is decomposition temperature, ${ }^{b}$ is the observed weight loss, ${ }^{c}$ is calculated weight loss.

\section{Surface area measurements}

Physical characteristics of the sorbent surface such as surface area and pore size distribution are critical factors in selecting a sorbent. Thus, $\mathrm{N}_{2}$ adsorption-desorption isotherms of BBN and PTBA were used to study the change in texture characteristics of the prepared sorbents and are shown in (Figure 4).

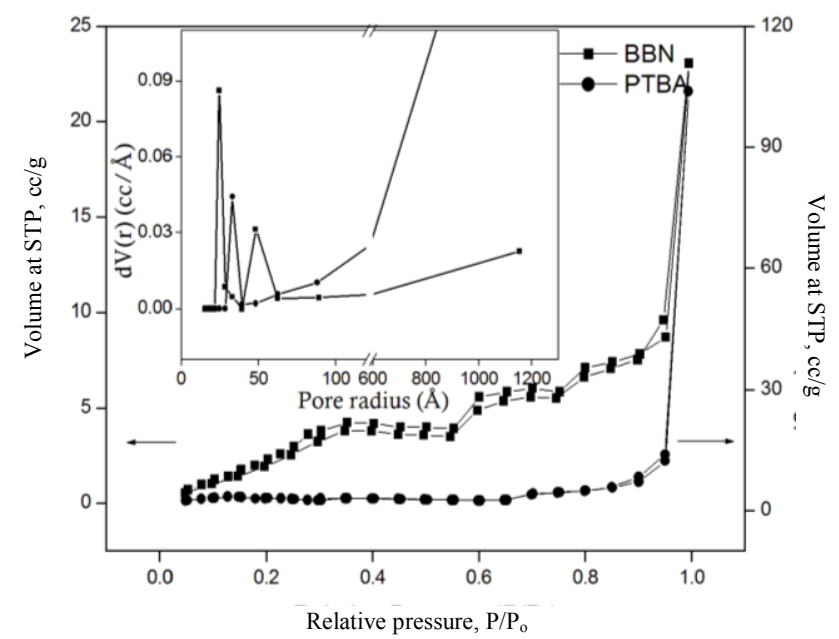

Figure 4. $\mathrm{N}_{2}$-adsorption-desorption isotherm and pore size distribution of BBN and PTBA sorbents. 
As illustrated in Figure 4, the $\mathrm{N}_{2}$-adsorption-desorption isotherm of BBN could be of type II isotherm according to the IUPAC classification, implying that the adsorption process may have resulted from the macropore adsorption behaviour ${ }^{20}$. The mesopore adsorption behaviour was also reported for this type of isotherm ${ }^{21}$. However, a small hysteresis loop type $\mathrm{H} 4$ of BBN may indicate the small contribution of mesopores and the pore shape is narrow and slit-like ${ }^{22}$. In contrast, PTBA has a type III isotherm which describes the weak interaction between adsorbent and adsorbate molecules on macro- or non-porous materials ${ }^{23}$. The absence of a hysteresis loop on PTBA may indicate that the sorbent became nonporous.

The pore size distributions determined by the BJH method are shown in the inset of Figure 4. It can be seen that the samples exhibit pore size distribution in the mesopore domain with a sharp increase in the macropore domain, indicating bimodal distributions.

The surface area, pore volume and radius of BBN are $11.3 \mathrm{~m}^{2} \mathrm{~g}^{-1}, 0.035 \mathrm{~cm}^{3} \mathrm{~g}^{-1}$ and $24.6 \AA$, respectively. The decrease in PTBA surface area $\left(6.3 \mathrm{~m}^{2} \mathrm{~g}^{-1}\right)$ can be attributed to aggregated $\mathrm{TiO}_{2}$ particles on its surface, which may acts as a plug to $\mathrm{N}_{2}$ molecules leading to the reduction of the surface area ${ }^{24}$. A more interesting point of texture properties of PTBA is the remarkable increase in pore volume $\left(0.134 \mathrm{~cm}^{3} \mathrm{~g}^{-1}\right)$ and pore diameter $(33.1 \AA)$ which can produce unique mesostructural features ${ }^{25}$.

\section{Morphology}

The morphological features of sorbent surfaces were studied using SEM and TEM images (Figure 5). Selected SEM images show that the morphological characteristics of BBN and PTBA sorbents consist of highly aggregated plate-like particles. However, selected TEM images revealed that the $\mathrm{BBN}$ aggregates are made up of spherical-like particles. $\mathrm{TiO}_{2}$ particles were deposited as aggregates of small spheres on PTBA surface. Some of them are discernable in Figure 5e. However, no trace of silver doping is observed which is probably attributed to minute amount of silver, i.e. $5 \% \mathrm{~mol} \mathrm{Ag.}$
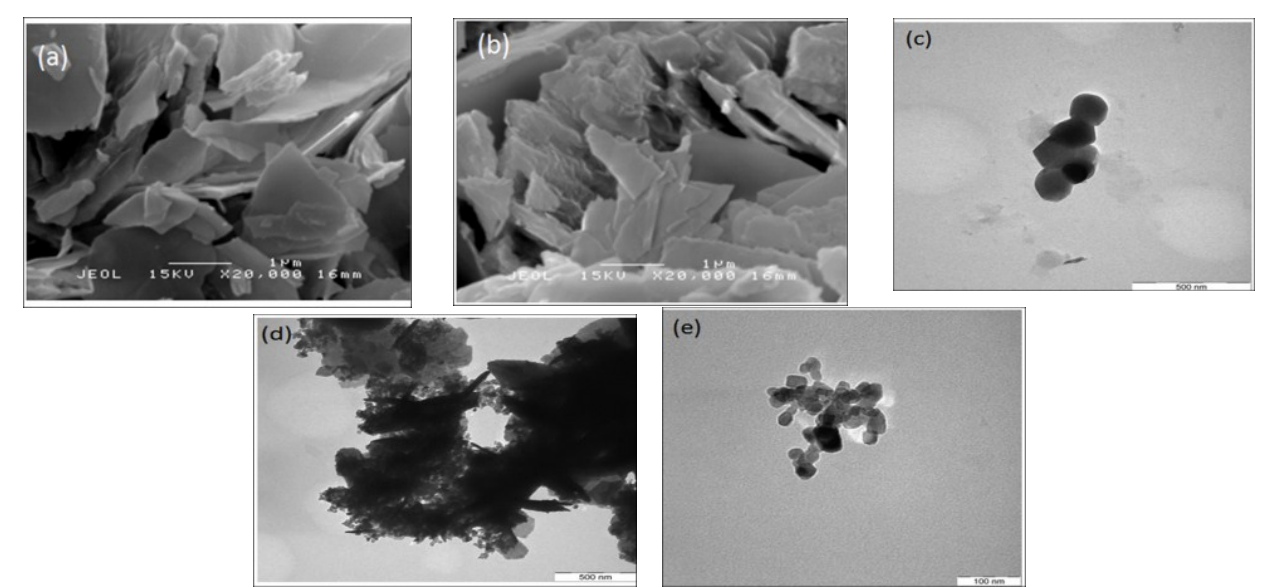

Figure 5. (a)SEM image of as-prepared BBN (b) SEM image of modified sample PTBA; (b) TEM image of BBN; (d) TEM image of PTBA and (e) shows the a magnified view of the dispersed $\mathrm{TiO}_{2}$ on PTBA surface.

\section{$X$-ray photoelectron spectroscopy (XPS)}

The intermolecular interactions between the functional groups of dyes and surface chemistry of the adsorbents are key factors in affecting adsorptive performance. Thus, to understand the 
differences in structure and surface chemistry between unmodified and $\mathrm{TiO}_{2}-\mathrm{Ag}$ modified sorbents, a detailed study of the valence states of the elements detected on BBN and PTBA surface was performed by using XPS. The peak positions are corrected for the surface charge using $\mathrm{C} 1 \mathrm{~s}$ peak at $284.5 \mathrm{eV}$ as a reference (Figure 6). As illustrated in Figure 6a, the $\mathrm{Bi} 4 \mathrm{f}$ core level spectra consist of single components for $\mathrm{Bi} 4 \mathrm{f}_{5 / 2}$ and $\mathrm{Bi} 4 \mathrm{f}_{7 / 2}$ peaks. The corresponding peaks of $\mathrm{Bi}_{4 / 2}$ and $\mathrm{Bi} 4 \mathrm{f}_{7 / 2}$ in $\mathrm{BBN}$ are located at binding energies of 165.1 and $159.8 \mathrm{eV}$, respectively, while those of $\mathrm{Bi} 4 \mathrm{f}_{5 / 2}$ and $\mathrm{Bi} 4 \mathrm{f}_{7 / 2}$ orbitals in PTBA are located at binding energies of 163.8 and $158.5 \mathrm{eV}$. The binding energies are consistent with those reported in $\mathrm{Bi}_{2} \mathrm{O}_{3}$, indicating the presence of trivalent oxidation state of bismuth centre in the prepared sorbents ${ }^{26}$. There were no obvious higher energy components corresponding to $\mathrm{Bi}^{5+}$. The shift towards lower binding energies of the PTBA sorbent indicates a change in the chemical states on the PTBA surface, which is in accordance with TGA results. In other words, this shift can be attributed to the difference in the chemical nature of the neighbouring atoms.
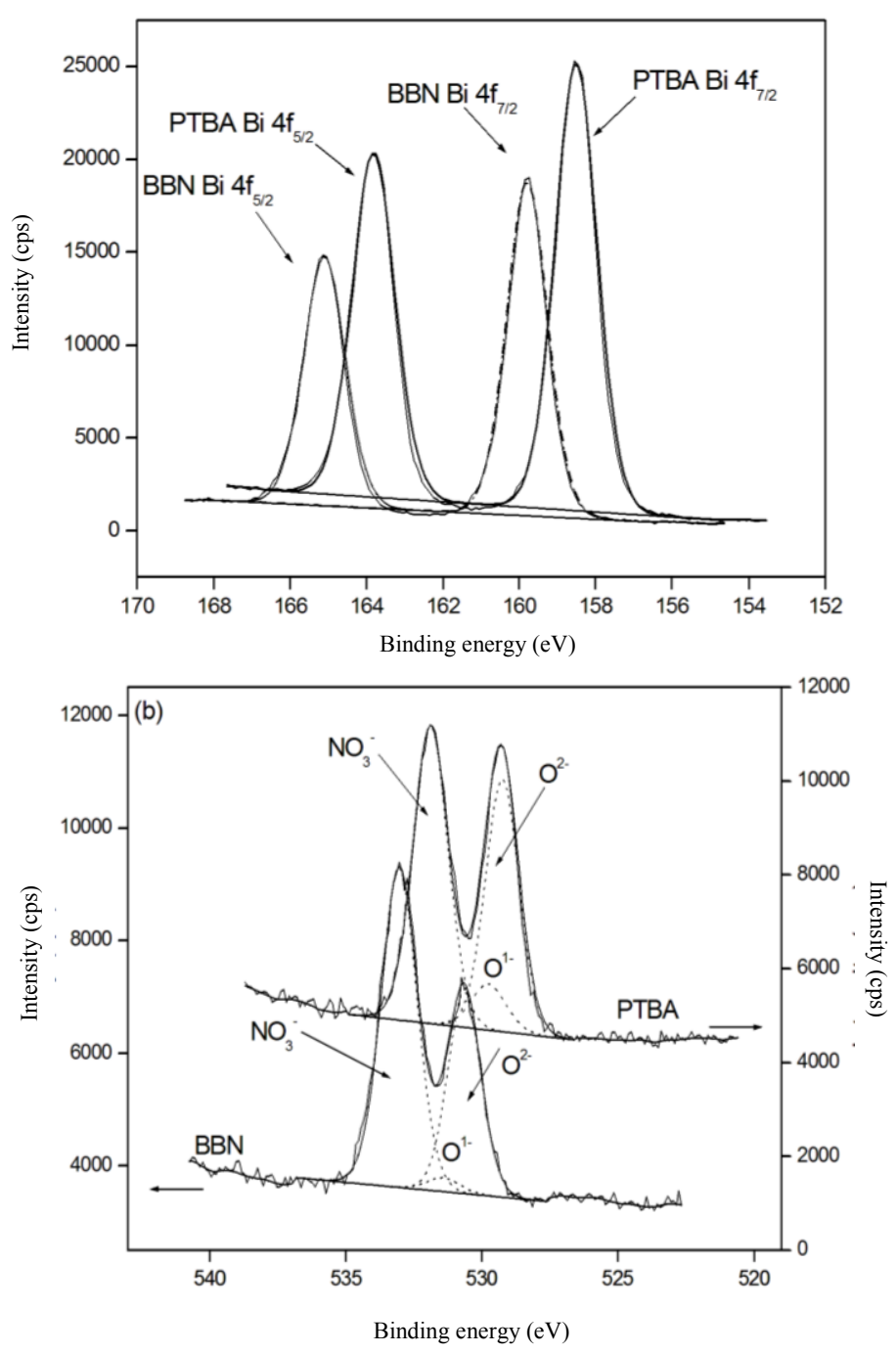

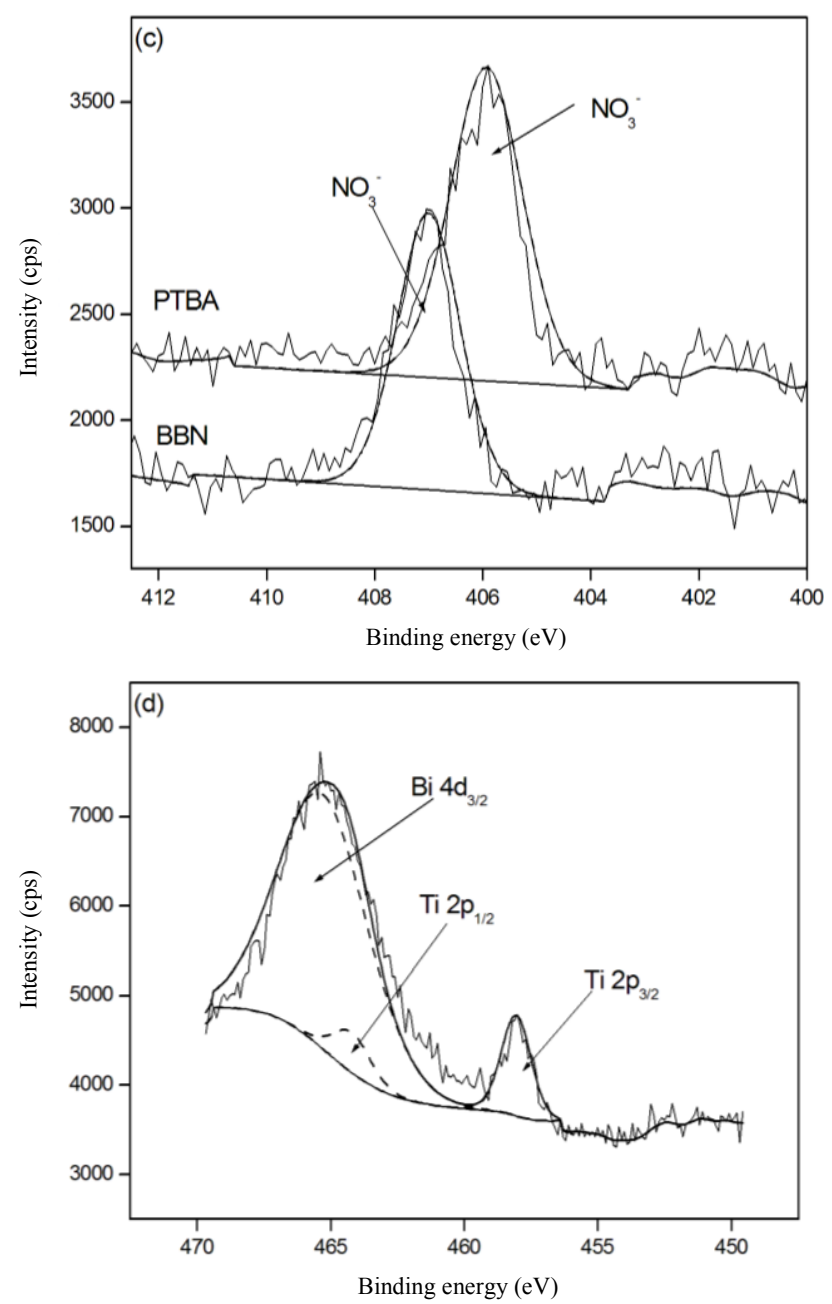

Figure 6. Deconvoluted XPS spectra of (a) Bi 4f (b) O 1s (c) N 1s and (d) Ti 2p regions of $\mathrm{BBN}$ and PTBA sorbents.

The Ti $2 p$ core level photoemission peak of PTBA sorbent overlapped with the Bi $4 d_{3 / 2}$ core level peak. By careful deconvolution, the binding energies of Ti $2 p_{1 / 2}$ and Ti $2 p_{3 / 2}$ were observed at 464.2 and $457.9 \mathrm{eV}$, respectively. The lower binding energy of Ti $2 \mathrm{p}_{3 / 2}$ suggests an octahedral coordination, segregation of $\mathrm{TiO}_{2}$ particles and high interactions with surface hydroxide groups, making the PTBA surface more hydrophilic if compared to $\mathrm{BBN}^{27-29}$.

The $\mathrm{O} 1 \mathrm{~s}$ core level peaks show a marked broadening towards higher binding energies, indicating the presence of high content oxygen groups on the surface of prepared sorbents that can be attributed to the presence of nitrates. When compared to PTBA, an overall shift of $1.2 \mathrm{eV}$ towards high binding energy is observed for O 1s core level peak on BBN's surface. This chemical shift is due to the presence of high content of nitrate groups in BBN sorbent.

The $\mathrm{N}$ 1s core level peaks indicate the existence of highly oxidized nitrogen atom on $\mathrm{BBN}$ and PTBA sorbents. The binding energies and their species are summarized in Table 2. 


\section{Atomic absorption spectrometer (AAS)}

Since a silver peak was not detected in the XPS analysis, the concentration of silver was determined by using AAS. The results showed that only a trace amount of silver (4.94 $\mathrm{mg})$ can be detected on the PTBA sorbent, compared to the theoretical value $(111 \mathrm{mg})$. This can be explained by the results of Mihalilovic et al., ${ }^{30}$ which showed that the presence of hydrophilic $\mathrm{TiO}_{2}$ particles made PTBA surface becomes more hydrophilic facilitated the subsequent interaction with hydrophilic Ag particles.

Table 2. XPS parameters for fitted peaks of BBN and PTBA sorbents.

\begin{tabular}{|c|c|c|c|}
\hline \multirow{2}{*}{$\begin{array}{l}\text { Core-level } \\
\text { region }\end{array}$} & \multicolumn{2}{|c|}{ Binding Energy $(\mathrm{eV})$} & \multirow{2}{*}{ Species } \\
\hline & $\mathrm{BBN}$ & PTBA & \\
\hline \multirow[t]{2}{*}{$\mathrm{Bi} 4 \mathrm{f}$} & 159.8 & 158.5 & $\mathrm{Bi} 4 \mathrm{f}_{7 / 2}$ \\
\hline & 165.1 & 163.8 & $\mathrm{Bi} 4 \mathrm{f}_{5 / 2}$ \\
\hline \multirow[t]{3}{*}{$\mathrm{O} 1 \mathrm{~s}$} & 530.6 & 529.3 & $\mathrm{O}^{2-}$ \\
\hline & 531.4 & 529.8 & $\mathrm{O}^{-1}$ of $\mathrm{OH}$ and $\mathrm{Ti}-\mathrm{OH}$ of octahedral $\mathrm{TiO}_{2}$ system \\
\hline & 533.1 & 531.9 & $\mathrm{NO}_{3}^{-}$ \\
\hline $\mathrm{N} 1 \mathrm{~s}$ & 406.9 & 405.9 & $\mathrm{NO}_{3}^{-}$ \\
\hline $\mathrm{C} 1 \mathrm{~s}$ & $\begin{array}{l}284.5 \\
286.8\end{array}$ & 284.5 & $\begin{array}{c}\mathrm{C} \text { atom } \\
\mathrm{CO}_{3}{ }^{2-} \text { surface impurities }\end{array}$ \\
\hline Ti $2 p$ & & $\begin{array}{l}457.9 \\
464.2\end{array}$ & Ti $2 p_{3 / 2}$ of octahedral coordination system \\
\hline $\mathrm{Bi} 4 \mathrm{~d}$ & & 465.2 & $\mathrm{Bi} 4 \mathrm{~d}_{3 / 2}$ \\
\hline
\end{tabular}

\section{Determination of $p H$ of zero point of charge $\left(\mathrm{pH}_{p z c}\right)$}

The point of zero charge of sorbent surface, $\mathrm{pH}_{\mathrm{pzc}}$, is the $\mathrm{pH}$ value, at which the concentration of acidic and basic species are equal ${ }^{31}$. The determination of $\mathrm{pH}_{\mathrm{pzc}}$ allows one to describe the ionization forms of functional groups and their interactions with the dye, leading to a better understanding of the adsorption mechanism. The $\mathrm{pH}_{\mathrm{pzc}}$ values of $\mathrm{BBN}$ and PTBA determined by batch equilibrium method (Figure 7) were found to be 6 and 6.6, respectively, indicating that the sorbent is slightly acidic. The difference in $\mathrm{pH}_{\mathrm{pzc}}$ values could be attributed to the structural change during modification. This agrees well with the assumption that each crystal surface possesses a unique set of potential determining surface groups and therefore should exhibit different acid/base characteristics ${ }^{32}$.

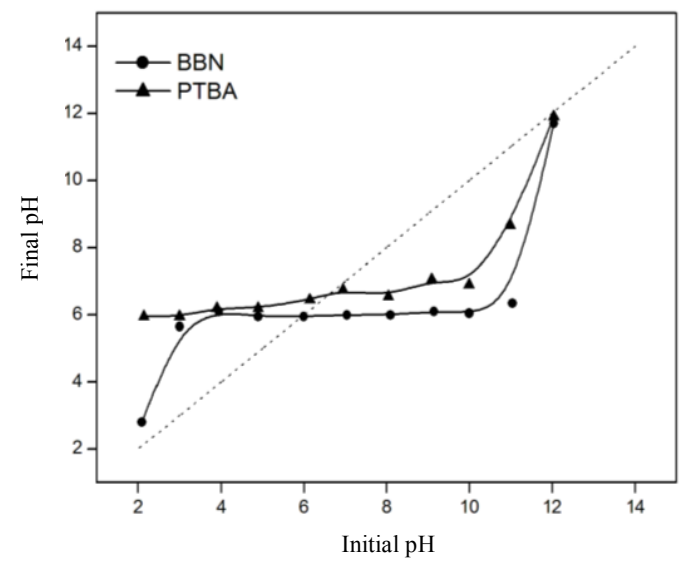

Figure 7. Determination of point of zero charge of BBN and PTBA. 


\section{Adsorption properties of prepared sorbents}

The adsorptive performance of prepared sorbents was evaluated using MO and SY dyes as model pollutants (Figure 8). Although it has lower surface area, PTBA exhibits higher sorption capacities when compared to BBN. This can be attributed to the presence of Ag and $\mathrm{TiO}_{2}$ particles which increase the hydrophilic character of the PTBA surface and enhance the electrostatic attraction with anionic dye molecules. In addition, the bigger pore volume and diameter of PTBA may play a role in promoting the adsorbability of dye molecules ${ }^{25}$. The results also showed that the adsorption capacity of SY dye was much lower if compared to the MO dye. This can be attributed to the presence of higher numbers of sulphonate groups on the SY dye that resist the adsorption onto synthesized sorbents ${ }^{33}$. In addition, the aggregation behaviour reported for the diluted solution of SY dye may also cause the monomer dye molecules unavailable for adsorption ${ }^{34}$.

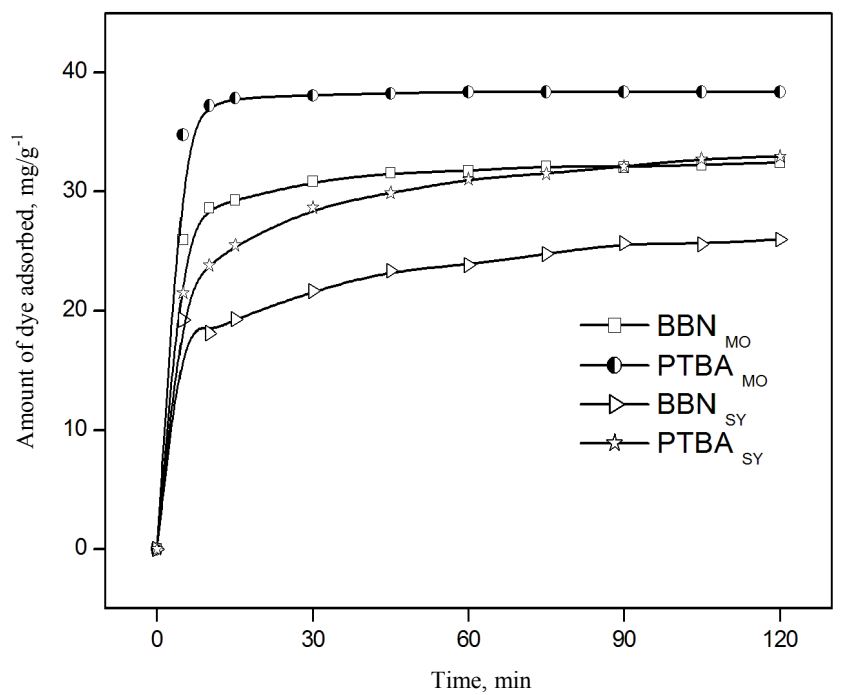

Figure 8. Evaluation of adsorptive performance of BBN and PTBA in removing $\mathrm{MO}$ and SY dyes from an aqueous solution.

\section{Conclusion}

The structural characteristics of bismuth basic nitrate and $\mathrm{TiO}_{2}-\mathrm{Ag}$ modified sorbent were firstly reported. The results showed that both sorbents could be indexed by the same cell parameters and may have the following structures $\mathrm{Bi}_{6} \mathrm{O}_{4}(\mathrm{OH})_{4}\left(\mathrm{NO}_{3}\right)_{6} .7 \mathrm{H}_{2} \mathrm{O}$ and $\mathrm{Bi}_{6} \mathrm{O}_{6}$ $(\mathrm{OH})_{2}\left(\mathrm{NO}_{3}\right)_{4} \cdot 1.5 \mathrm{H}_{2} \mathrm{O}$, for $\mathrm{BBN}$ and PTBA, respectively. Nitrate, water molecules and hydroxyl groups are the main functional groups detected on the sorbents' surface. Although $\mathrm{TiO}_{2}$ particles were deposited on the BBN surface, there was a remarkable change in $\mathrm{pH}_{\mathrm{pzc}}$, pore volume and diameter. The change or the increase of hydrophilic character of PTBA surface as a result of presence of octahedral $\mathrm{TiO}_{2}$ and hydrophilic $\mathrm{Ag}$ particles in combination with the change in surface texture properties played a vital role to improve and facilitate the adsorbability of dyes onto PTBA sorbent.

\section{Acknowledgment}

The authors would like to acknowledge the financial support of Taiz University, Yemen in providing scholarship to Eshraq. 


\section{References}

1. Christensen A N, Chevallier M A, Skibsted J and Iversen B B, J Chem Soc Talton Trans., 2000, 265.

2. Christensen A N, Jensen T R, Scarlett N V Y, Madsen I C, Hanson J C and Altomare A, Roy Soc Chem., 2003, 3278.

3. Lazarini F, Thermochim Acta, 1981, 46, 53.

4. Henry N, Evain M, Deniard P, Jobic S, Mentre O and Abraham F, J Solid State Chem., 2003, 176, 127.

5. Udalova T A, Logutenko O A, Timakova E V, Afonina L I, Naydenko E S and Yukhin Y M, New Mater Technol., 2008, 137.

6. Henry N, Mentre O, Abraham F, Maclean E Jand Roussel P, J Solid State Chem 2006, 179, 3087.

7. Kodama H, Bull Chem Soc JPN., 1994, 67, 1788.

8. Fritsche U, J Environ Sci Heal., 1993, A28, 1903.

9. El-Qada E N, Allen S J and Walker G M, Chem Eng J., 2008, 135, 174.

10. Afkhami A, Saber-Tehrani M and Bagheri H, Desalination., 2010, 263, 240.

11. Krishna B S, Murty D S R and Prakash B S J, Appl Clay Sci., 2001, 20, 65.

12. Enomoto N, Kawasaki K, Yoshida M, Li X, Uehara M and Hojo J, Solid state Ionics., 2002, 151, 171.

13. Samokhvalov A, Nair S, Duin E C and Tatarchuk B J, Appl Surf Sci., 2010, 256, 3647.

14. Yamashita H and Choi H, J Hazard Mater., 2010, 182557.

15. Sukhov B G, Mukha S A, Antipova I A, Svetlana A, Medvedeva A, Larina L I, Chipanina N N, Kazheva O N, Gennadii B, Shilov V, Dyachenko O A and Trofimova B A, Arkivoc., 2008, viii, 139.

16. Wajima T, Umet Y, Narita S and Sugawara K, Desalination., 2009, 249, 323.

17. Reddy K R k, Suneetha P, Karigar C S, Manjunath N H and Mahendra K N, J Chil Chem Soc., 2008, 53, 1653.

18. Irmawati R, Nasriah M N N, Taufiq-Yap Y H and Hamid S B A, Catal Today, 2004, 93-95, 701.

19. Fruth V, Popa M, Berger D, Ionica C M and Jitianu M, J EurCeram Soc., 2004, 24, 1295.

20. Kang S, Yu J S, Kruk M and Jaroniec M, Chem Commun., 2002, 1671.

21. Chen S, Zhang J, Zhang C, Yue Q, Li Y and Li C, Desalination., 2010, 252, 149.

22. Qing W, Guojun j, Hongpeng L, Jingru B and Shaohua L, Oil Shale., 2010, 27, 135.

23. Prahas D, Kartika Y, Indraswati N and Ismadji S, Chem Eng J., 2008, 140, 32.

24. Jiang J Q, Cooper C and Ouki S, Chemosphere., 2002, 47, 711.

25. Long C, Lu Z, Li A, Liu W, Jiang Z, Chen J and Zhang Q, Sep Purif Technol., 2005, 44, 115.

26. Jing-jing X, Min-dong C and De-gang F, Trans Nonferrous Met Soc China, 2011, 21, 340.

27. Nocun M, Mozgawa W, Jedlinski J and Najman J, J Mol struct., 2005, 744-747, 603.

28. Capel-Sanchez M C, Campos-Martin J M and Fierro J L G, J Catal., 2005, 234, 488.

29. Moretti G, Salvi A M, Guascito M R and Langerame F, Surf Interface Anal., 2004, 36, 1402.

30. Mihailovic D, Saponjic Z, Vodnik V, Potkonjak B, Jovancic P, Nedeljkovic J M and Radetic M, Polym Adv Technol., 2010, 22: n/a.doi 10.1002/pat. 1752.

31. Cardenas-Lopez C, Camargo G, Giraldo L and Moreno-Pirajan J C, Ecl Quim Sao Paulo., 2007, 32, 61.

32. Fitts J P, Shang X, Flynn G W, Heinz T F and Eisenthal K B, J Phys Chem B, 2005, 109, 7981.

33. Oh M J and Kim J P, Dyes Pigm., 2006, 70, 220.

34. Renshaw M P and Day I J, J Phys Chem B, 2010, 114, 10032. 


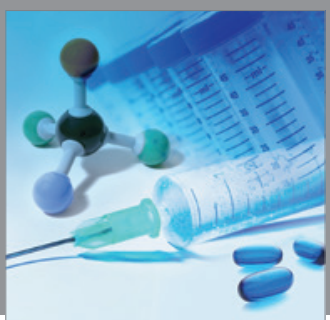

International Journal of

Medicinal Chemistry

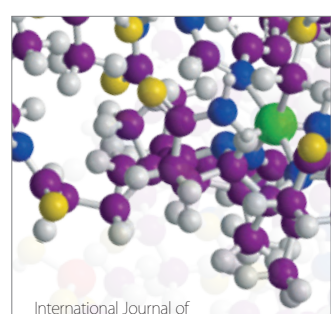

Carbohydrate Chemistry

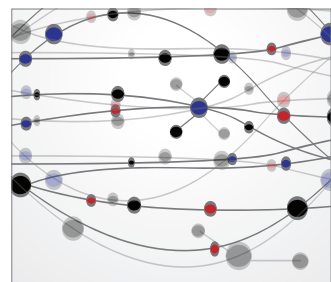

The Scientific World Journal
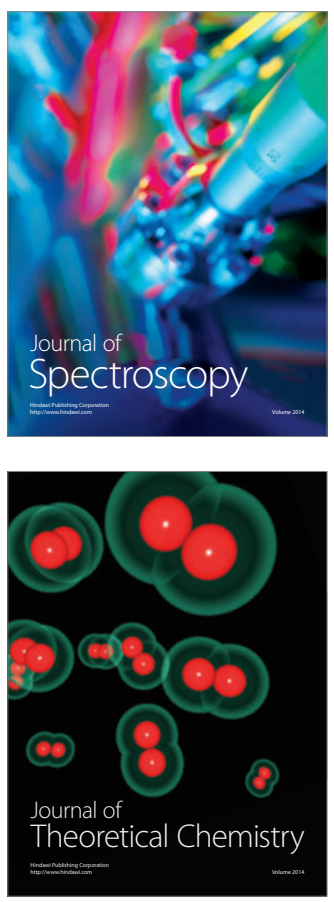
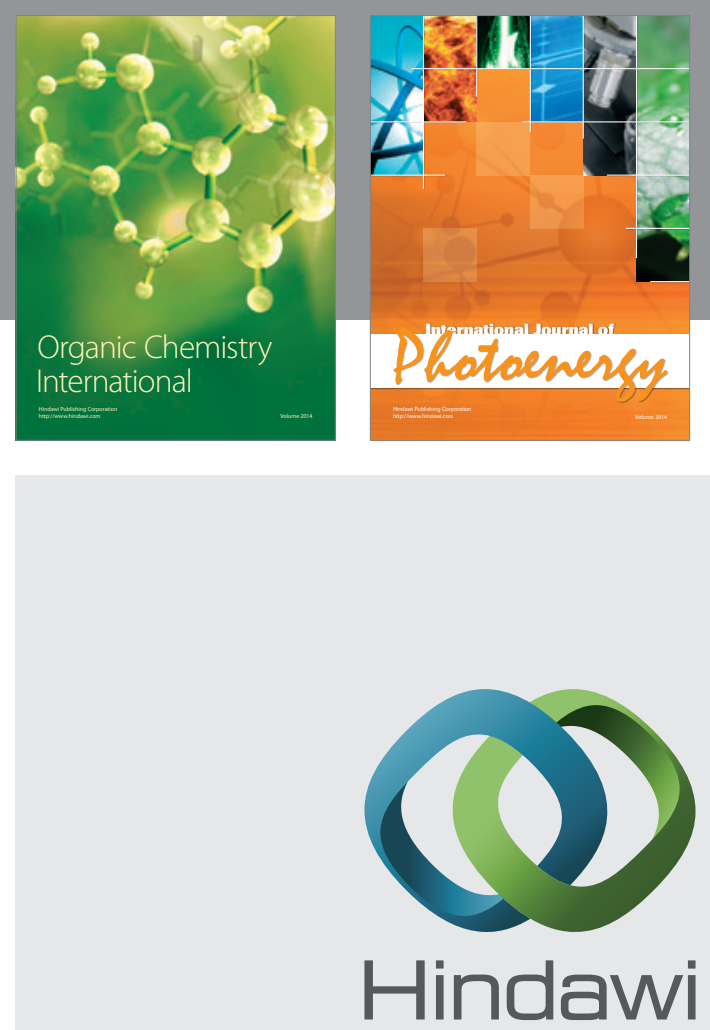

Submit your manuscripts at

http://www.hindawi.com
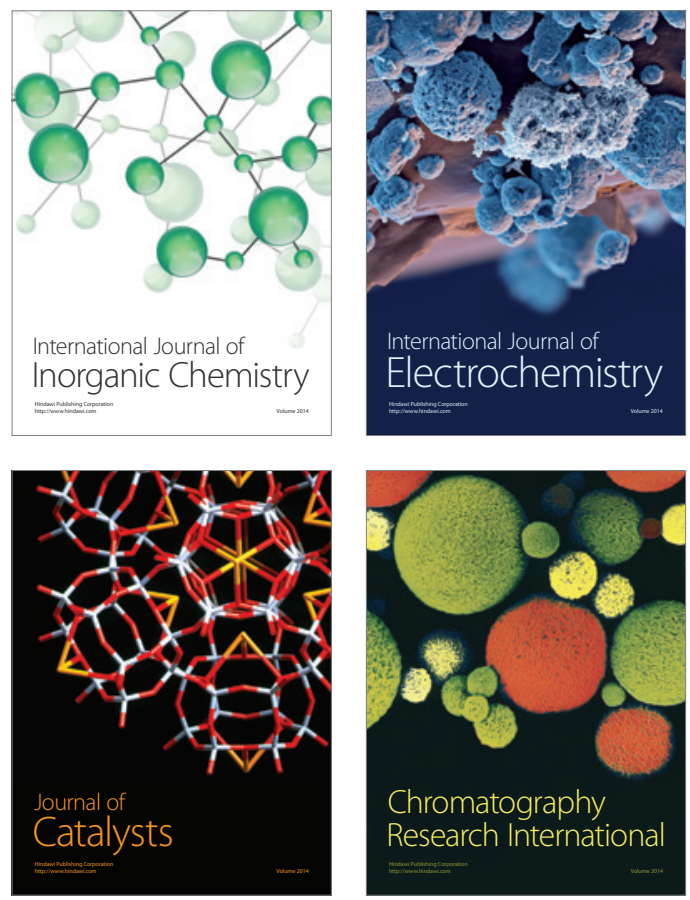
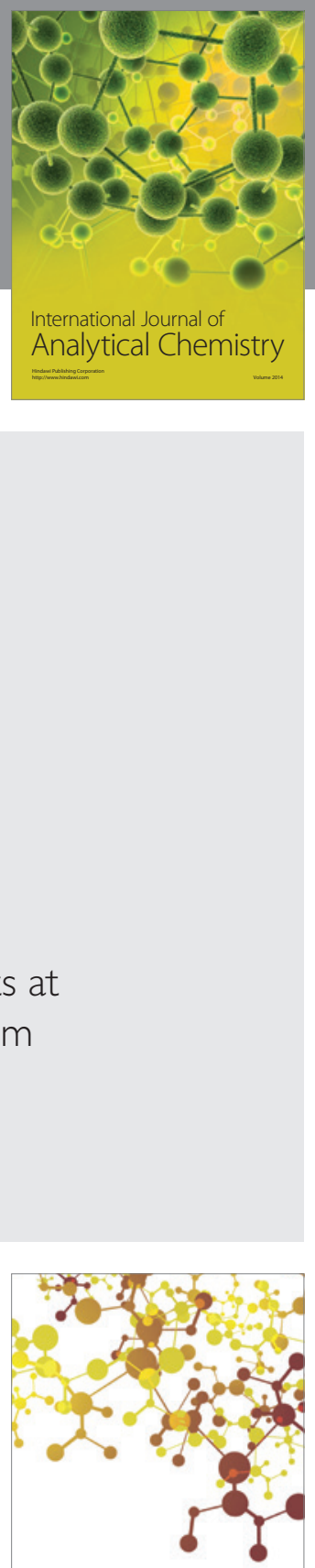

Journal of

Applied Chemistry
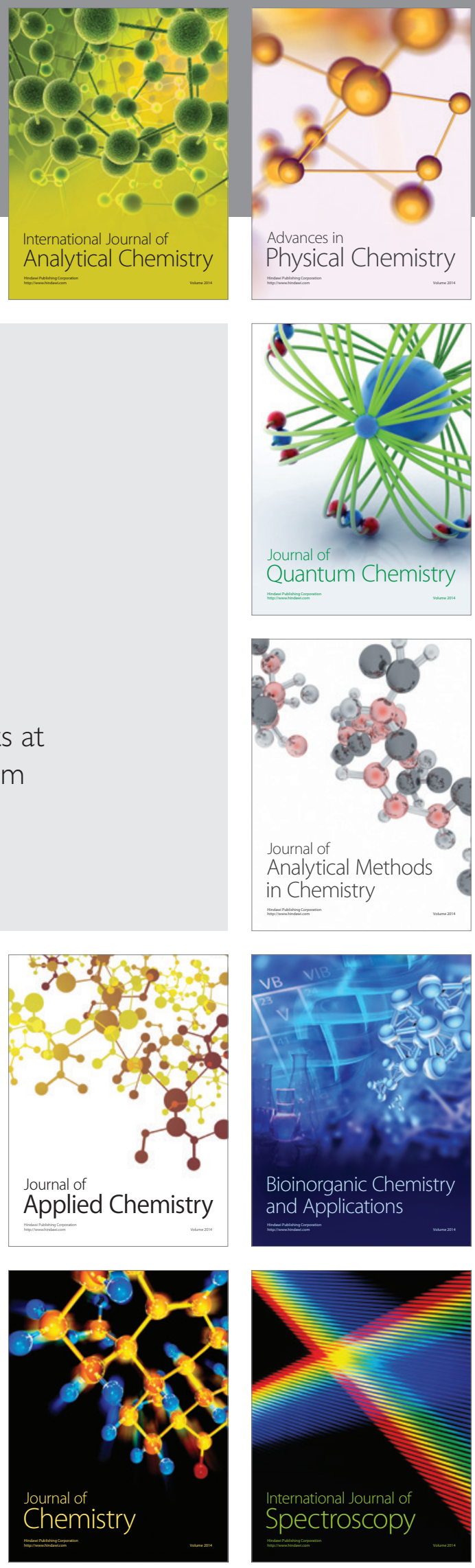